\title{
PENGEMBANGAN MEDIA KARTU KATA DALAM PEMBELAJARAN BAHASA INDONESIA BAGI PENUTUR ASING
}

\author{
Sulistia Ellsa ${ }^{1}$, Laili Etika Rahmawati ${ }^{2}$ \\ Program Studi Pendidikan Bahasa dan Sastra Indonesia, Universitas Muhammadiyah Surakarta ${ }^{1,2}$ \\ Email: sulistiaellsa18@gmail.com ${ }^{1}$
}

\begin{abstract}
Abstrak
Pesatnya perkembangan pembelajaran BIPA belum ditunjang dengan media pembelajaran yang memadai. Minimnya media pembelajaran BIPA mempengaruhi motivasi belajar dan capaian tujuan pembelajaran. Tujuan penelitian ini, yaitu mendeskripsikan proses pengembangan Kartu Kata sebagai media pembelajaran yang akan diterapkan pada mahasiswa BIPA tingkat A1 di Universitas Muhammadiyah Surakarta. Penelitian ini menggunakan rancangan penelitian pengembangan (Research and Development) dengan mengadaptasi model Sukmadinata, metode yang digunakan dalam mengumpulkan data adalah metode pencatatan dokumen dan wawancara yang kemudian dianalisis dengan menggunakan metode deskriptif kualitatif. Subjek dalam penelitian ini adalah mahasiswa BIPA Tingkat A1 di Universitas Muhammadiyah Surakarta Tahun ajaran 2019/2020. Objek penelitian adalah pengembangan media pembelajaran Kartu Kata. Hasil dari penelitian ini menunjukkan bahwa desain pengembangan media Kartu Kata sudah sesuai dengan prinsip penyusunan media visual dan sesuai dengan SKL (Standar Kompetensi Lulusan) atau bahan ajar BIPA Tingkat A1.
\end{abstract}

Kata Kunci : Pengembangan Media, Media Pembelajaran, BIPA, Kartu Kata

\begin{abstract}
The rapid development of BIPA learning has not been supported by adequate learning media. The lack of BIPA learning media influences learning motivation and achievement of learning objectives. The purpose of this study is to describe the process of developing a Word Card as a learning medium that will be applied to BIPA level Al students at the Muhammadiyah University of Surakarta. This research used development research design (Research and Development) by adapting the Sukmadinata model, the method used in gathering data was method of recording documents and interviews which was then analyzed using the method qualitative descriptive. The subjects in this study were BIPA Level Al students at Muhammadiyah University, Surakarta. The object of research was the development of the word card learning media. The results of this study indicate that the design of the word card media development is in accordance with the principles of the preparation of visual media and in accordance with SKL (Graduate Competence Standard) or BIPA Level Al teaching materials.
\end{abstract}

Key Words : Media development, Learning Media, BIPA, Word Cards

\section{PENDAHULUAN}

Pesatnya perkembangan pembelajaran BIPA saat ini berpengaruh pada kebutuhan media pembelajaran. Perkembangan itu belum ditunjang dengan media pembelajaran yang memadai dengan kata lain ketersediaan media masih dikatakan minim. Penggunaan media pembelajaran akan mempengaruhi kualitas capaian pembelajaran itu sendiri. Media pembelajaran dapat memberikan stimulus atau rangsangan dalam belajar, baik mempelajari empat aspek keterampilan berbahasa yang meliputi menyimak, berbicara, membaca dan menulis maupun penguasaan kosakata bagi mahasiswa BIPA.

Meningkatnya minat negara lain dalam mempelajari Bahasa Indonesia menjadi salah satu faktor meningkatnya pembelajaran BIPA di Indonesia. Ada lebih dari 35 Negara yang mempelajari Bahasa Indonesia [1]. Hal ini berkaitan dengan diresmikannya bahasa Indonesia sebagai bahasa resmi ASEAN [2]. Mahasiswa pemelajar BIPA berbeda dengan mahasiswa pemelajar bahasa pada 
umumnya, mereka merupakan pelajar asing dengan latar belakang bahasa dan budaya yang berbeda. Hal-hal yang menjadi pembeda antara pemelajar BIPA dengan mahasiswa umum yaitu (1) jangkauan dan target hasil pembelajaran mahasiswa BIPA lebih tegas; (2) latar belakang pendidikan, dimana mahasiswa BIPA pada umumnya merupakan orangorang terpelajar; (3) latar belakang budaya yang mendominasi dan menjadi suatu ciri gaya belajar yang khas; (4) minat dan motivasi yang tinggi pemelajar BIPA dalam mempelajari bahasa Indonesia; (5) latar belakang disiplin ilmu yang berbeda; dan (6) perbedaan bahasa pertama atau bahasa ibu yang menimbulkan kesulitan dalam belajar terutama dalam masalah pelafalan maupun penulisan [3].

Pemelajar BIPA merupakan mahasiswa dengan latar belakang bahasa pertama yang berbeda-beda. Pemelajar BIPA kelas pemula belum menguasai bahasa target secara memadai untuk dapat menjalin komunikasi, hal ini ditandai dengan dengan aktivitas komunikasi yang terbatas tentang materi yang dipelajari [4]. Bahasa pertama seorang pemelajar BIPA akan mempengaruhi pemilihan materi yang diajarkan [5]. Setiap pemelajar BIPA yang akan belajar bahasa Indonesia melalui lembaga bahasa perlu mengisi formulir analisis kebutuhan yang diperlukan, tujuannya agar mempermudah pengajar dalam menyusun bahan maupun media pembelajaran yang perlu diterapkan sehingga tujuan pembelajaran dapat tercapai [3].

Tidak menutup kemungkinan selama pembelajaran seorang akan menghadapi sebuah masalah, yang akhirnya berdampak pada peserta didik yang tidak mampu belajar secara maksimal, efektif dan efisien. Penyebabnya bisa karena kondisi kelas yang monoton dan membosankan, tidak bervariasinya model pembelajaran yang digunakan, maupun minimnya penggunaan media pembelajaran. Hal-hal itulah yang akhirnya memberikan dampak buruk terhadap minat belajar siswa.

Berdasarkan hasil wawancara dengan salah satu dosen ahli pengajar BIPA di Universitas Muhammadiyah Surakarta, terdapat beberapa masalah yang kerap kali muncul dalam pembelajaran BIPA di Universitas Muhammadiyah Surakarta. Kondisi kelas yang pasif semakin mempersulit pembelajaran, dosen lebih cenderung memodifikasi metode pembelajaran misal dengan menunjukkan gambar dari leptop melalui layar LCD, namun hal tersebut belum dapat memaksimalkan efektivitas pembelajaran. Mahasiswa akan cenderung bermain gawai ketika pembelajaran tanpa media atau metode yang dapat menarik perhatian mereka. Penggunaan media dalam pembelajaran BIPA dirasa sangat penting, namun butuh waktu lama untuk membuat atau mengembangkan sebuah media. Universitas Muhammadiyah Surakarta dipergunakan sebagai tempat penelitian karena terdapat permasalahan yang berkaitan dengan ketersediaan media pembelajaran yang kurang variatif.

Media pembelajaran merupakan alat atau segala sesuatu yang mampu memberikan atau menyalurkan informasi kepada pemelajar [6], [7], [8]. Media pembelajaran dalam kelas BIPA juga memiliki fungsi yang sama, yaitu sebagai media, perantara atau alat yang digunakan untuk menyampaikan informasi, baik berupa materi pembelajaran maupun informasi lain. Media pembelajaran bahasa Indonesia bagi penutur asing merupakan sarana yang digunakan untuk melatih keterampilan berbahasa seorang pemelajar BIPA [9]. Fungsi media dalam pembelajaran adalah (1) dengan media pembelajaran, materi pembelajaran yang disampaikan seragam; (2) pembelajaran menjadi menarik dan 
lebih jelas; (3) pembelajaran yang lebih interaktif; (4) efisiensi waktu dan tenaga; (5) meningkatkan kualitas capaian pembelajaran; (6) pembelajaran dapat dilakukan dimana dan kapan saja; (7) menumbuhkan sikap posistif baik pada materi maupun proses pembelajaran; (8) mengubah materi yang abstrak menjadi lebih konkrit; (9) mengatasi keterbatasan ruang dan waktu; dan (10) mengatasi keterbatasan indera manusia [6].

Penelitian serupa mengenai BIPA pernah dilakukan oleh Randi Ramliyana. Penelitian tersebut menggunakan rancangan penelitian pengembangan (Research and Development) dengan metode pengumpulan data yang digunakan yaitu pencatatan dokumen, wawancara dan angket. Subjek dalam penelitian tersebut adalah pebelajar BIPA pemula di Undiksha, dan objek dalam penelitian ini adalah pengembangan media pembelajaran flashcard [10]. Yang kedua adalah penelitian yang dilakukan oleh Prima Vidya Asteria, dalam penelitiannya menggunakan rancangan pengembangan dengan metode R\&D (Research and Development). Subjek dalam penelitian tersebut adalah mahasiswa BIPA Unesa dan objek dalam penelitian tersebut adalah pengembangan media e-komik dalam pembelajaran [11].

Penelitian sejenis yang ketiga mengenai BIPA dilakukan oleh $\mathrm{Ni}$ Made Candra Puspita Lestar. Penelitian tersebut berbeda dengan peneltian sejenis yang pernah dilakukan, penelitian tersebut menggunakan rancangan penelitian pengembangan (Research and Development) dengan menggunakan model pengembangan ADDIE, subjek dalam penelitian tersebut adalah mahasiswa BIPA pemula di Undiksha dengan objek penelitian adalah pengembangan media pembelajaran visual berupa flashcard [3].
Penelitian pengembangan ini diharapkan dapat menghasilkan luran produk berupa media pembelajaran BIPA untuk pemelajar tingkat A1 atau tingkat pemula. Di samping itu, diharapkan melalui media pembelajaran dapat meningkatkan motivasi dan capaian pembelajaran. Penulis mencoba mengembangkan media pembelajaran Kartu Kata yang disesuaikan dengan SKL (Standar Kompetensi Lulusan) dalam Permendikbud No. 27 Tahun 2017 mengenai Identifikasi kata dan frasa yang berkaitan dengan arah, lokasi, lingkungan sekitar, dan aktivitas seharihari [12]. Media pembelajaran ini berupa kartu yang berisi gambar dan berpasangan dengan kartu yang berisi makna/arti dari gambar. Media Kartu Kata terdiri dari 40 (empat puluh) pasang kartu.

Berdasarkan permasalahan yang telah dipaparkan, penelitian ini bertujuan mendeskripsikan proses pengembangan media pembelajaran Kartu Kata bagi pemelajar BIPA tingkat A1 di Universiitas Muhammadiyah Surakarta. Manfaat dari penelitian ini yaitu memberikan variasi media pembelajaran yang berbeda sehingga dapat menunjang perkembangan pembelajaran BIPA, meningkatkan motivasi belajar peserta didik dengan menciptakan suasana belajar yang edukatif serta meningkatkan capaian pembelajaran.

\section{METODE}

Penelitian ini menggunakan rancangan penelitian pengembangan dengan metode R\&D (Research and Development). Penelitian ini menggunakan model Sukmadinata yang kemudian diadaptasi sesuai dengan kebutuhan [13]. Tahapan yang perlu ditempuh untuk dapat mendesain produk hanya pada tahap ketiga. 


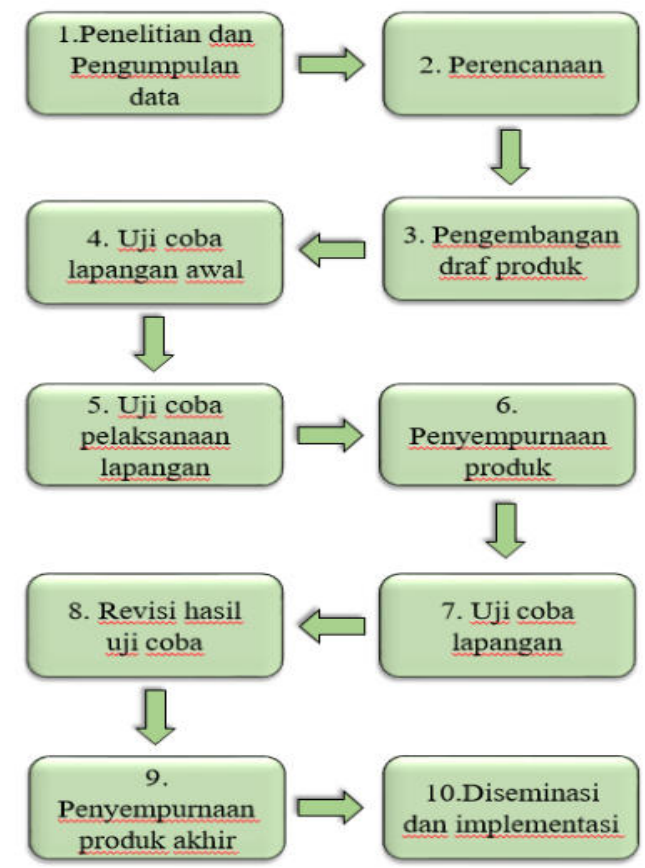

Gambar 1. Tahapan Pengembangan R\&D

Subjek dalam penelitian ini adalah 12 mahasiswa BIPA tingkat A1 di Universitas Muhammadiyah Surakarta Tahun 2019. Objek dalam penelitian ini adalah pengembangan media pembelajaran Kartu Kata yang akan diterapkan pengajar di kelas BIPA dalam mata kuliah berbicara.

\section{Penelitian dan Pengumpulan Data}

Teknik pengumpulan data dalam penelitian ini menggunakan teknik wawancara dan pengamatan. Teknik analisis data menggunakan teknik deskriptif kualitatif untuk menarik kesimpulan dari data yang telah diperoleh.

\section{Perencanaan}

Pada tahap perencanaan produk beberapa kegiatan yang dilakukan yaitu analisis karakteristik mahasiswa BIPA tingkat A1 di UMS, analisis kebutuhan media pembelajaran, dan materi yang akan disampaikan melalui media pembelajaran Kartu Kata.

1. Analisis Karakter Mahasiswa

Hal ini dilakukan untuk mengetahui kebiasaan belajar, sikap dan situasi belajar siswa sebagai pandangan dan acuan dalam mengembangkan media Kartu Kata.

2. Analisis Kebutuhan

Langkah ini dilakukan untuk mengetahui ketersediaan media pembelajaran dan menentukan kompetensi yang perlu dipelajari oleh mahasiswa BIPA tingkat A1, sehingga pengembangan media Kartu Kata dapat sesuai dengan kebutuhan.

3. Analisis Materi Pembelajaran

Langkah ini dilakukan agar penyusunan media pembelajaran Kartu Kata sesuai dengan kompetensi atau SKL (Standar Kompetensi Lulusan) dan/atau materi ajar BIPA tingkat A1.

\section{Pengembangan Draf Produk}

Berdasarkan tahap perencanaan pengembangan draf produk ini melewati 6 tahapan pengeditan. Adapun tahap tersebut yaitu, tahap new layer, tahap pembuatan bingkai, tahap insert picturel insert text, tahap pemberiaan warna, dam tahap penyimpanan.

\section{HASIL DAN PEMBAHASAN}

Media pembelajaran BIPA merupakan sesuatu yang digunakan untuk mempermudah mengajarkan bahasa Indonesia bagi penutur asing [14]. Tujuan pembelajaran BIPA, yaitu (1) penguasaan kemampuan berbahasa penutur asing yang reseptif dan produktif; (2) menambah pengetahuan budaya, adat, dan sistem sosial di Indonesia; (3) penguasaan bahasa Indonesia untuk mengembangkan ilmu pengetahuan, komunikasi, bisnis dan bidang lainnya [15].

Media pembelajaran Kartu Kata didesain menggunakan aplikasi Corel Draw versi $\mathrm{X} 8$ yang dalam penggunaanya lebih mudah dan terdapat banyak vitur yang menarik. Jenis huruf yang digunakan pada desain media ini yaitu Geometr415 Blk BT dikarenakan jenis huruf ini mudah dibaca 
dan tebal meskipun dengan ukuran huruf 20 points. Pemilihan warna latar belakang yang lebih soft atau tidak mencolok agar tidak terlalu mendominasi dan tidak bersaing dengan gambar maupun kata-kata yang terdapat dalam kartu. Pengembangan media kartu kata tetap berpegang pada prinsip pembuatan media yaitu sederhana, kesesuaian antara gambar dan tulisan kepaduan warna dan lainnya.

Beberapa prinsip dalam penggunaan media visual sebagai berikut: 1) unsur dalam media meliputi gambar maupun bahan dibuat sesederhana mungkin, penempatan dan pemberian warna pada unsur pemanis (desain bingkai, warna latar belakang) tidak boleh menghalangi unsur utama yang akan diinformasikan agar mudah dipahami oleh pemakai media, dan 3) konsep antara kata dan gambar harus sesuai dan saling berkaitan [3].

Media Kartu Kata dibuat dari bahan kertas karton tebal berukuran $15 \times 9,7 \mathrm{~cm}$, setiap kartu bergambar akan memiliki kartu pasangan yang berisi kata-kata yang berkaitan dengan gambar. Tujuan mengapa gambar dan kata dibuat terpisah agar kartu kata dapat menciptakan suasana belajar yang kritis dan agar mahasiswa mau bereksplorasi mencari jawaban yang sesuai untuk gambar yang ditunjukkan.

Desain Media disusun secara sistematis dan menarik agar mampu meningkatkan minat belajar dan motivasi belajar mahasiswa BIPA yang cenderung pasif. Desain dan materi pada media kartu kata dikembangkan sesuai dengan SKL (Standar Kompetensi Lulusan) untuk pemelajar BIPA tingkat A1 sehingga kompetensi dan kebutuhan mahasiswa dapat tercapai. Penggunaan sebuah media pembelajaran yang menarik dapat mendukung tercapainya tujuan pembelajaran [16].
Media pembelajaran harus dapat meningkatkan motivasi belajar, merangsang pemelajar untuk mengingat materi yang disampaikan, menciptakan suasana belajar aktif dan pemelajar yang responsif, dan mendorong siswa melakukan praktik belajar dengan benar agar fungsi media pembelajaran dapat berjalan dengan tepat dan sesuai [17]. Kosakata yang menjadi acuan dalam penyusunan kartu kata adalah sebagai berikut.

Tabel 1. Daftar Kosakata Arah \& Lokasi

\begin{tabular}{|c|c|c|}
\hline No & Kata/Frasa & Arti \\
\hline 1. & Timur & East \\
\hline 2. & Tenggara & Southeast \\
\hline 3. & Selatan & South \\
\hline 4. & Barat Daya & Southwest \\
\hline 5. & Barat & West \\
\hline 6. & Barat Laut & Northwest \\
\hline 7. & Utara & North \\
\hline 8. & Timur Laut & Northeast \\
\hline 9. & Belok kiri & Turn left \\
\hline 10. & Belok kanan & Turn right \\
\hline 11. & Lurus terus & Keep straight \\
\hline 12. & Pertigaan & t-junction \\
\hline 13. & Bundaran & roundabout \\
\hline 14. & Palang kereta & Railroad crossing \\
\hline 15. & Tempat Parkir & Parking lot \\
\hline 16. & Dilarang Parkir & No Parking \\
\hline 17. & Larangan & Turn not right \\
\hline & $\begin{array}{l}\text { Berbelok ke } \\
\text { kanan }\end{array}$ & \\
\hline 18. & $\begin{array}{l}\text { Larangan } \\
\text { Berbelok ke kiri }\end{array}$ & $\begin{array}{l}\text { Turn left not } \\
\text { allowed }\end{array}$ \\
\hline 19. & $\begin{array}{l}\text { Penyempitan } \\
\text { jalan }\end{array}$ & $\begin{array}{l}\text { Narrowing of the } \\
\text { road }\end{array}$ \\
\hline 20. & $\begin{array}{l}\text { Penyebrangan } \\
\text { orang }\end{array}$ & Zebra cross \\
\hline 21. & Hati-hati & Have a care \\
\hline 22. & $\begin{array}{l}\text { Lalu lintas dua } \\
\text { arah }\end{array}$ & Two-way traffic \\
\hline 23. & $\begin{array}{l}\text { Persimpangan } \\
\text { empat arah }\end{array}$ & $\begin{array}{l}\text { Four-way } \\
\text { intersection }\end{array}$ \\
\hline
\end{tabular}

Kata di atas digunakan sebagai bahan dalam penyusunan media pembelajaran 
Kartu Kata. Adapun desain Kartu Kata tersebut adalah sebagai berikut.

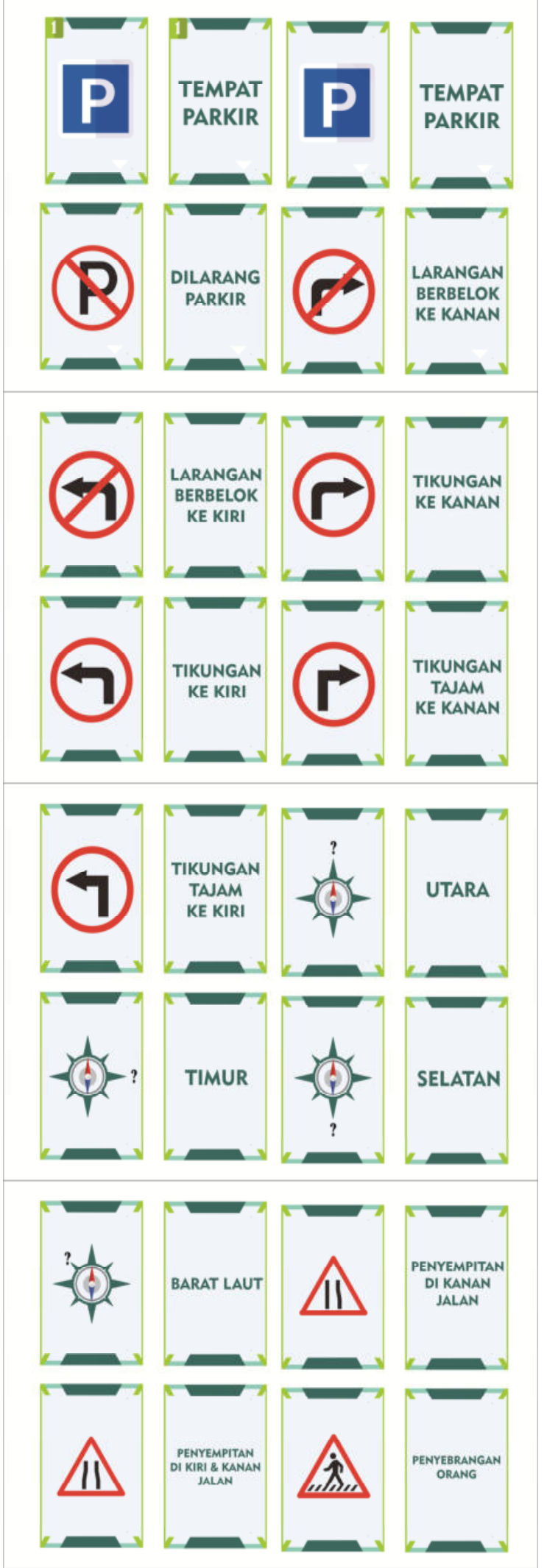

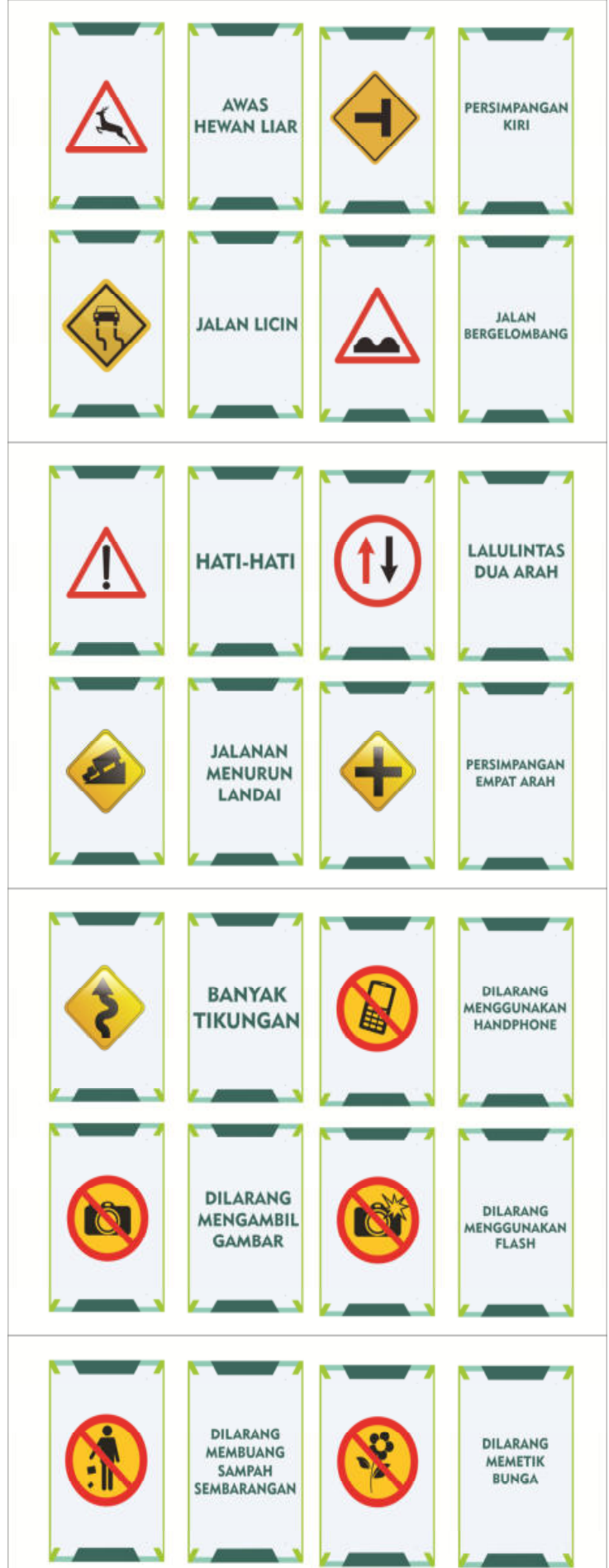

Gambar 2. Desain Kartu Kata

Media Kartu Kata dapat diterapkan dengan dua metode, yaitu siswa diberikan beberapa kartu yang berisi kata/makna sebuah gambar, kemudian pembelajar menunjukan kartu yang berisi gambar dan 
meminta siswa untuk memberi jawaban dengan menggunakan kartu yang mereka pegang, atau sebaliknya peserta didik yang diberi kartu bergambar dan dosen bertanya menggunakan kartu yang berisi kata/makna.

\section{SIMPULAN}

Berdasarkan hasil penelitian dan pembahasan, dapat ditarik kesimpulan sebagai berikut. (1) Pengembangan media Kartu Kata sebagai media pembelajaran yang akan digunakan pada mahasiswa BIPA tingkat A1 di Universitas Muhammadiyah Surakarta dikembangkan dengan berbagai tahapan, mulai dari study eksplorasi dan pengamatan terhadap suatu kondisi belajar siswa, analisis kebutuhan siswa akan media pembelajaran serta relevansi antara materi pembelajaran dengan media yang hendak dikembangkan yang berdasarkan pada SKL (Standar Kompetensi Lulusan). (2) Media Kartu Kata dirancang dan disusun sesuai prinsip pengembangan media pembelajaran dan kebutuhan siswa akan media pembelajaran. Media Kartu Kata terdiri dari dua kartu yang berpasangan, hal ini agar media tersebut selain dapat menambah pengetahuan mengenai kosakata namun juga menciptakan suasana belajar yang aktif, kritis dan eksploratif.

\section{DAFTAR PUSTAKA}

[1] A. K. Sutrisno. "Analisis Asesmen Keterampilan Berbicara dalam Pembelajaran BIPA Program CLS 2013". NOSI, vol. 2, no. 1, pp. 1-13, 2014.

[2] Y. Purwiyanti, S. Suwandi, dan Andayani. "Pengembangan Kompetensi Percakapan Pemelajar Bahasa Indonesia Penutur Asing dengan Strategi Simulasi Percakapan (Permainan Peran dan SosioDeama)". in The 1st Education and Language International Conference
Proceedings, pp. 922-928, 2017.

[3] N. M. C. P. Lestari, I. M. Sutama, dan I. D. G. B. Utama. "Pengembangan Media Pembelajaran Visual bagi Pebelajar BIPA Pemula di Undiksha". $J$. Pendidik. Bhs. dan Sastra Indones. Undiksha, vol. 8, no. 2, pp. 86-95, 2018.

[4] L. E. Rahmawati dan D. M. Gajewski. "Urgensi Penilaian dalam Pembelajaran BIPA". Prosiding Seminar Nasional KBSP V, pp. 153156, 2018.

[5] M. Isnaini. "Pengajaran BIPA dengan Media Gambar-Tulis Narasi". Seminar Kepakaran BIPA 1, 2016, pp. 223-236, 2016.

[6] I. Falahudin. "Pemanfaatan Media dalam Pembelajaran". J. Lingk. Widyaiswara, vol. 1, no. 4, pp. 104117, 2014.

[7] M. Fadhli. "Pengembangan Media Pembelajaran Berbasis Video Kelas IV Sekolah Dasar". J. Dimens. Pendidik. dan Pembelajaran, vol. 3, no. 1, pp. 24-29, 2015.

[8] Mawardi. "Merancang Model dan Media Pembelajaran". Sch. J. Pendidik. dan Kebud., vol. 8, no. 1, pp. 26-40, 2018.

[9] R. Agustina, Andayani, dan N. E. Wardani. "Implementasi Pembelajaran Bahasa Indonesia bagi Penutur Asing di UPT P2B Universitas Sebelas Maret Surakarta". J. Pendidik. Bhs. dan Sastra Indones., vol. 1, no. 2, pp. 140-154, 2013.

[10] R. Ramliyana. "Penerapan Media Komik pada Pembelajaran BIPA (Studi Kasus pada Peserta Korea Tingkat Pemula di Universitas Trisakti Jakarta )". J. SAP, vol. 1, no. 1, pp. 8-17, 2016.

[11] P. V. Asteria dan D. N. Farida. "EMikuta (Komik Saku Kosakata Elektronik): Media Pembelajaran 
BIPA Berbasis Teknologi”. Kongres Bahasa Indonesia, pp. 1-14, 2009.

[12] M. Pendidikan, D. Kebudayaan, dan R. Indonesia. Peraturan Metreri Pendidikan dan Kebudayaan Republik Indonesia Nomor 27 Tahun 2017. 2017.

[13] Alexon dan N. S. Sukmadinata. "Pengembangan Model Pembelajaran Terpadu Berbasis Budaya untuk Meningkatkan Apresiasi Siswa terhadap Budaya Lokal". Cakrawala Pendidik., vol. 29, no. 2, pp. 189-203, 2010.

[14] F. Arvianto. "Media Pembelajaran dalam Pengajaran BIPA (Bahasa Indonesia bagi Penutur Asing)". Seminar Nasional Pendidikan, pp. 293-298, 2017.

[15] N. Setyaningsih, R. A. Nugroho, dan V. W. Suryaningtyas.
"Pengembangan Materi BIPA Berbasis Multimedia dan Berkonten Budaya Lokal". Culture, vol. 3, no. 1, pp. 42-63, 2016.

[16] C. Nuraini. "Pengaruh Keterkaitan Konten dengan Gambar yang Sesuai dengan Makna yang Terungkap pada Pembelajaran BIPA". J. Sasindo Unpam, vol. 6, no. 1, pp. 67-75, 2018.

[17] N. Meifiani dan T. D. Prastyo. "Pengembangan Media Pembelajaran Peluang Berbasis Multimedia Interaktif untuk Mahasiswa STKIP PGRI Pacitan". $J$. Beta, vol. 8, no. 2, pp. 153-162, 2015.

[18] N. Novianti dan I. Nurlaelawati. Sahabatku Indonesia Tingkat A1, 1st ed. Jakarta: Kementrian Pendidikan dan Kebudayaan, 2016. 